\title{
A peptide from Porphyra yezoensis stimulates the proliferation of IEC-6 cells by activating the insulin-like growth factor I receptor signaling pathway
}

\author{
MIN-KYEONG LEE ${ }^{1}$, IN-HYE KIM ${ }^{2}$, YOUN-HEE CHOI ${ }^{2}$ and TAEK-JEONG NAM ${ }^{1,2}$ \\ ${ }^{1}$ Department of Food Science and Nutrition, Pukyong National University, Busan 608-737; ${ }^{2}$ Institute of Fisheries Science, \\ Pukyong National University, Busan 619-911, Republic of Korea
}

Received May 8, 2014; Accepted December 8, 2014

DOI: $10.3892 /$ ijmm.2014.2037

\begin{abstract}
Porphyra yezoensis (P. yezoensis) is the most noteworthy red alga and is mainly consumed in China, Japan and Korea. In the present study, the effects of a $P$. yezoensis peptide (PY-PE) on cell proliferation and the associated signaling pathways were examined in IEC-6 rat intestinal epithelial cells. First, the MTS assay showed that PY-PE induced cell proliferation in a dose-dependent manner. Subsequently, the mechanism behind the proliferative activity induced by PY-PE was determined. The insulin-like growth factor-I receptor (IGF-IR) signaling pathway was the main focus as it plays an important role in the regulation of cell growth and proliferation. PY-PE increased the protein and mRNA expression of IGF-IR, insulin receptor substrate-1, Shc and PY-99. In addition, PY-PE stimulated extracellular signal-regulated kinase phosphorylation and phosphatidylinositol 3-kinase/Akt activation but inhibited p38 and c-Jun N-terminal kinase phosphorylation. Furthermore, PY-PE treatment increased protein and mRNA expression levels of activator protein-1, which regulates cell proliferation and survival, in the nuclear fraction. These results have significant implications for understanding the role of cell proliferation signaling pathways in intestinal epithelial cells.
\end{abstract}

\section{Introduction}

Red seaweeds have attracted increasing attention in recent years through research aimed to develop new medicines and healthy diets from bioactive compounds (1).Porphyra yezoensis (P. yezoensis) is a critical alga that is mainly consumed in Korea, China and Japan. This alga is an important source of

Correspondence to: Professor Taek-Jeong Nam, Department of Food Science and Nutrition, Pukyong National University, 599-1 Daeyeon 3-Dong, Nam-gu, Busan 608-737, Republic of Korea E-mail: namtj@pknu.ac.kr

Key words: Porphyra yezoensis, proliferation, insulin-like growth factor-I receptor signaling pathway physiologically active substances, such as sulfated polysaccharides, polyphenols and peptides, with biological effects including antitumor (2), anti-inflammatory (3), antioxidant (4) and blood pressure effects (5). The majority of studies on the biological activities of $P$. yezoensis have been conducted in vivo. In the present study, the induction of proliferation was examined in intestinal epithelial cells by a peptide from P. yezoensis.

Activation of the insulin-like growth factor-I receptor (IGF-IR) via autocrine, paracrine and endocrine mechanisms appears to play an important role in regulating cell growth, proliferation and differentiation (6). The insulin receptor substrate (IRS) family (IRS-1 to IRS-4) and Shc are the best characterized substrates of IGF-IR. The IRS proteins are docking proteins that potentially bind to IGF-IR and recruit several effector proteins through Src homology 2 (SH2) domain interactions $(7,8)$. Shc is a substrate of tyrosine kinase receptors, non-receptor kinases and certain phosphatases $(9,10)$. Upon stimulation with IGF-I, tyrosine phosphorylation sites in the IRS proteins bind to phosphotyrosine-containing binding motifs (YXXM) within $\mathrm{SH} 2$ domains in several downstream signaling molecules, including growth factor receptor-bound protein $2, \mathrm{SH} 2$-containing protein-tyrosine phosphatase 2 and the p85 regulatory subunit of phosphatidylinositol 3-kinase (PI3K) (11). Receptor activation leads to activation of various signaling pathways, including mitogen-activated protein kinase (MAPK) cascades (12). $\mathrm{PI} 3 \mathrm{~K}$ is a critical regulatory protein involved in intracellular signal transduction processes and controlling major cellular functions (13). Activated PI3K catalyzes the phosphorylation of the membrane phospholipid phosphatidylinositol 4,5-bisphosphate to generate phosphatidylinositol 3,4,5-trisphosphate, thereby producing a lipid-binding site on the cell membrane for the serine/threonine kinase Akt (14). Akt is activated by phosphorylation at $\mathrm{Thr}^{308}$ and $\mathrm{Ser}^{473}$ residues by two phosphoinositide-dependent protein kinases, PDK1 and PDK2 (15). Akt controls cell survival, proliferation, growth and motility (16). In mammalian cells, MAPK cascades constitute a large kinase network that regulates a variety of biological processes, including cell growth, proliferation, differentiation and inflammatory responses (17). The p42/p44 MAPK [extracellular signal-regulated kinase 
(ERK)] signal transduction pathway is activated by various mitogens. By contrast, c-Jun N-terminal kinase (JNK) and p38 pathways are mainly activated by cellular stress and inflammatory cytokines. Notably, ERK is associated with cell proliferation and growth $(18,19)$.

Activator protein-1 (AP-1) comprises homodimers and heterodimers composed of basic-region leucine zipper proteins that belong to the Jun (c-Jun, v-Jun and Jun D) and Fos (c-Fos, v-Fos and Fos B) families, as well as the associated activating transcription factors (ATF2, B-ATF and ATF3/LRF1) $(20,21)$. AP-1 regulation is induced by various stimuli, including growth factors, cytokines and ultraviolet (UV) irradiation. In addition, three different types of MAPKs (ERK, JNK and fos-regulating kinase) contribute to induction of AP-1 activity in response to a diverse array of extracellular stimuli (22). Jun-Fos (heterodimeric) and Jun-Jun (homodimeric) complexes preferentially bind to the 12- $O$-tetredecanoylphorbol-13-acetate-responsive element (23). The AP-1 complex mediates responses to cellular signals by binding to DNA and inducing gene transcription changes leading to physiological activity in the cell. AP-1 thereby regulates numerous cellular processes, including cell proliferation, differentiation and stress responses (24).

In the present study, a peptide from P. yezoensis (known as PY-PE) is shown to have proliferative effects on IEC-6 intestinal epithelial cells. The intracellular mechanism of PY-PE was determined, focusing on the IGF-IR signaling pathway, which is involved in the regulation of cellular proliferation and differentiation.

\section{Materials and methods}

Preparation of PY-PE. PY-PE (A-L-E-G-G-K-S-S-G-G-G-EA-T-R-D-P-E-P-T) was synthesized by Peptron, Inc. (Daejeon, Korea).Purification of PY-PE was performed using the Shimadzu Prominence HPLC apparatus and a C18 column (Capcell Pak; Shiseido, Tokyo, Japan) in $0.1 \%$ trifluoroacetic acid (TFA)/water and a gradient of $10-70 \%$ acetonitrile $(0 \%$ acetonitrile in $2 \mathrm{~min}$, $0-30 \%$ acetonitrile in $10 \mathrm{~min}, 30-90 \%$ acetonitrile in $2 \mathrm{~min}$ ) in $0.1 \% \mathrm{TFA}$, with a flow rate of $1 \mathrm{ml} / \mathrm{min}$ and UV detection at $220 \mathrm{~nm}$, controlled using the software package Class-VP, 6.14 (Kyoto, Japan). The molecular weight of PY-PE was determined to be $1,916 \mathrm{kDa}$ (Fig. 1) using a mass spectrometer (HP 1100 Series LC/MSD; Agilent Technologies, Santa Clara, CA, USA).

Cell culture. IEC-6 rat small intestinal epithelial cells (ATCC CRL-1592) were obtained from the American Type Culture Collection (Rockville, MD, USA). Cells were maintained in a humidified $5 \% \mathrm{CO}_{2}$ incubator at $37^{\circ} \mathrm{C}$ in Dulbecco's modified Eagle's medium supplemented with $10 \%$ fetal bovine serum (HyClone, Inc., South Logan, UT, USA), $100 \mathrm{U} / \mathrm{ml}$ penicillin and $100 \mathrm{mg} / \mathrm{ml}$ streptomycin. The medium was replaced every 2 days.

Cell proliferation assay. Cell proliferation was estimated using a CellTiter $96^{\circledR}$ aqueous non-radioactive cell proliferation assay (Promega, Madison, WI, USA), which is based on the cleavage of 3-(4,5-dimethylthiazol-2-yl)-5-(3-carboxymethoxyphenyl)-2-(4-sulfonyl)-2H-tetrazolium (MTS) into a formazan product that is soluble in tissue culture medium. Cells were seeded in 96 -well plates at $1 \times 10^{4}$ cells/well in

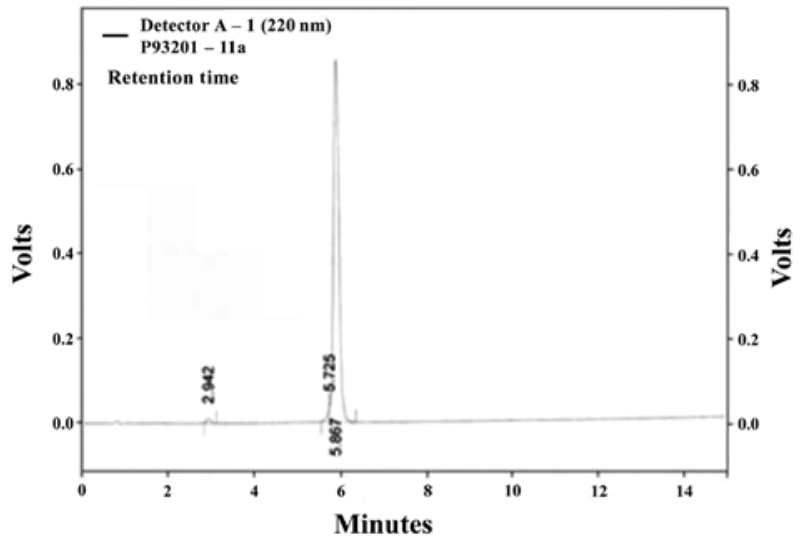

Figure 1. Purification of the peptide from P. yezoensis (PY-PE) by Shiseido Capcell Pak C18 column chromatography.

$100 \mu \mathrm{l}$ medium and attached for $24 \mathrm{~h}$. Attached cells were maintained in serum-free medium (SFM) for $4 \mathrm{~h}$ and were subsequently treated with PY-PE $(125-1,000 \mathrm{ng} / \mathrm{ml})$ for $24 \mathrm{~h}$. The cells were incubated with $10 \mu \mathrm{l}$ MTS solution for $30 \mathrm{~min}$, and the absorbance of each well was measured at $490 \mathrm{~nm}$ using a SpectraMax 340PC microplate reader (Molecular Devices, Sunnyvale, CA, USA).

Extraction of whole-cell protein lysates. IEC-6 cells were plated in $100-\mathrm{mm}$ dishes at a density of $2 \times 10^{4}$ cells $/ \mathrm{ml}$ and cultured to $60 \%$ confluence at $37^{\circ} \mathrm{C}$. The cells were subsequently incubated for $24 \mathrm{~h}$ in SFM containing $0,125,250,500$ or 1,000 ng/ml PY-PE. Cells were washed with phosphate-buffered saline and suspended on ice in lysis buffer [50 $\mathrm{mM}$ Tris, $5 \mathrm{mM}$ EDTA, $150 \mathrm{mM} \mathrm{NaCl}$ and $1 \%$ Triton X-100 (pH 7.5)] containing protease inhibitors $(1 \mathrm{mg} / \mathrm{ml}$ aprotinin, $1 \mathrm{mg} / \mathrm{ml}$ leupeptin, $1 \mathrm{mg} / \mathrm{ml}$ pepstatin $\mathrm{A}, 200 \mathrm{mM} \mathrm{Na} \mathrm{VO}_{4}, 500 \mathrm{mM}$ $\mathrm{NaF}$ and $100 \mathrm{mM}$ PMSF). The extracts were centrifuged at $14,000 \mathrm{rpm}(10,770 \mathrm{xg})$ for $10 \mathrm{~min}$, and the supernatant was used for western blot analysis.

Extraction of nuclear lysates. Cells were treated and harvested as described above, lysed with hypotonic lysis buffer [10 mM 4-(2-hydroxyethyl)-1-piperazineethanesulfonic acid)(HEPES) (pH 7.9), $10 \mathrm{mM} \mathrm{KCl}$ and $1.5 \mathrm{mM} \mathrm{MgCl}_{2}$, and incubated for $15 \mathrm{~min}$ at $4^{\circ} \mathrm{C}$. Cells were lysed further by the addition of $2.5 \% \mathrm{NP}-40$ and incubated for $10 \mathrm{~min}$ at $4^{\circ} \mathrm{C}$. After $10 \mathrm{~min}$, nuclei were collected by centrifugation at $5,000 \mathrm{rpm}(1,593 \mathrm{x} \mathrm{g})$ for $5 \mathrm{~min}$ at $4^{\circ} \mathrm{C}$. Nuclear proteins were resuspended in extraction buffer [10 mM HEPES ( $\mathrm{pH} 7.9)$, $100 \mathrm{mM} \mathrm{NaCl}, 1.5 \mathrm{mM} \mathrm{MgCl} 2,0.1 \mathrm{mM}$ EDTA and $0.1 \mathrm{mM}$ dithiothreitol] and incubated for $20 \mathrm{~min}$ at $4^{\circ} \mathrm{C}$. The extracts were centrifuged at $14,000 \mathrm{rpm}(10,770 \mathrm{x} \mathrm{g})$ for $10 \mathrm{~min}$ and the supernatant was used for western blot analysis.

Western blot analysis. Protein extracts $(30 \mu \mathrm{g})$ were separated by $7.5-12.5 \%$ sodium dodecyl sulfate-polyacrylamide gel electrophoresis and transferred to polyvinylidene fluoride membranes (Millipore, Billerica, MA, USA). Membranes were blocked with $1 \%$ bovine serum albumin (BSA) in TBS-T $[10 \mathrm{mM}$ Tris-HCl, $150 \mathrm{mM} \mathrm{NaCl}(\mathrm{pH} 7.5)$ and $0.1 \%$ Tween-20] and incubated overnight with the indicated 
Table I. Oligonucleotide sequences of the primers used in RT-PCR.

\begin{tabular}{ll}
\hline Gene name & \multicolumn{1}{c}{ Primer sequence (5'-3') } \\
\hline IGF-IR & F: AAA-TGT-GCC-CGA-GCG-TGT-G \\
& R: TGC-CCT-TGA-AGA-TGG-TGC-ATC \\
IRS-1 & F: ACT-TGA-GCT-ATG-ACA-CGG-CT \\
& R: GGT-TGG-AGC-AAC-TGG-ATG-AA \\
PI3K & F: GCC-GAA-CAC-CTT-TTT-GAG-TC \\
& R: AGG-AGC-GGT-ACA-GCA-AAG-AA \\
PDK1 & F: AAG-GGT-ACG-GGC-CTC-TCA-AA \\
& R: CCC-ACG-TGA-TGG-ACT-GAA-AGA \\
Akt & F: CAA-CTT-CTC-TGR-GGC-GCA-GTG \\
& R: GAC-AGG-TGG-AAG-AAC-AGC-TCG \\
$c-J u n$ & F: TCA-AAA-TGT-TTG-CAA-CTG-CTG-CG \\
& R: ATG-ACT-GCA-AAG-ATG-GAA-ACG \\
$c-F o s$ & F: GGA-GAA-TCC-GAA-GGA-AGG \\
& R: GCT-TGG-GCT-CAG-GGT-CAT-TG \\
GAPDH & F: CAG-CCG-AGC-CAC-ATC-G \\
& R: TGA-GGC-TGT-TGT-CAT-ACT-TCT-C
\end{tabular}

F, forward; R, reverse; RT-PCR, reverse transcription-polymerase chain reaction; IGF-IR, insulin-like growth factor-I receptor; IRS-1, insulin receptor substrate-1; PI3K, phosphatidylinositol 3-kinase; PDK1, phosphoinositide-dependent protein kinase 1; GAPDH, glyceraldehyde 3-phosphate dehydrogenase.

primary antibodies (diluted 1:500, 1:1,000 or 1:2,000; Santa Cruz Biotechnology, Inc., Santa Cruz, CA, USA) in TBS-T containing $1 \%$ BSA with gentle agitation at $4^{\circ} \mathrm{C}$. The secondary antibody was a horseradish peroxidase-conjugated goat anti-mouse or anti-rabbit antibody (A90-116P; diluted 1:10,000; Bethyl Laboratories, Inc., Montgomery, TX, USA). The signals were detected using an enhanced chemiluminescence Western blotting kit (Thermo Fisher Scientific, Inc., Rockford, IL, USA).

Reverse transcription-polymerase chain reaction (RT-PCR). The mRNA expression levels of specific genes were evaluated by RT-PCR. IEC- 6 cells were seeded in 100-mm dishes at a density of $2 \times 10^{4}$ cells/well and were cultured for $24 \mathrm{~h}$, after which the medium was replaced with SFM containing PY-PE $(125,250,500$ or $1,000 \mathrm{ng} / \mathrm{ml})$ for $24 \mathrm{~h}$. RNA was extracted from cells using the TRIzol reagent (Invitrogen Life Technologies, Carlsbad, CA, USA) and quantified using oligo(dT) primers (Intron Biotechnology Co., Ltd., Seongnam, Korea). cDNA was reverse transcribed from the RNA and subjected to amplification using a PCR kit (dNTP mix, 10X Ex Taq Buffer and Ex Taq; Takara Bio, Inc., Shiga, Japan) with primers (Table I) in $0.1 \%$ diethylpyrocarbonate water. PCR products were resolved on $1 \%$ agarose gels. Gels were stained with $10 \mathrm{mg} / \mathrm{ml}$ ethidium bromide to visualize the amplification products.

Statistical analysis. Significant differences among multiple mean values were assessed by analysis of variance using

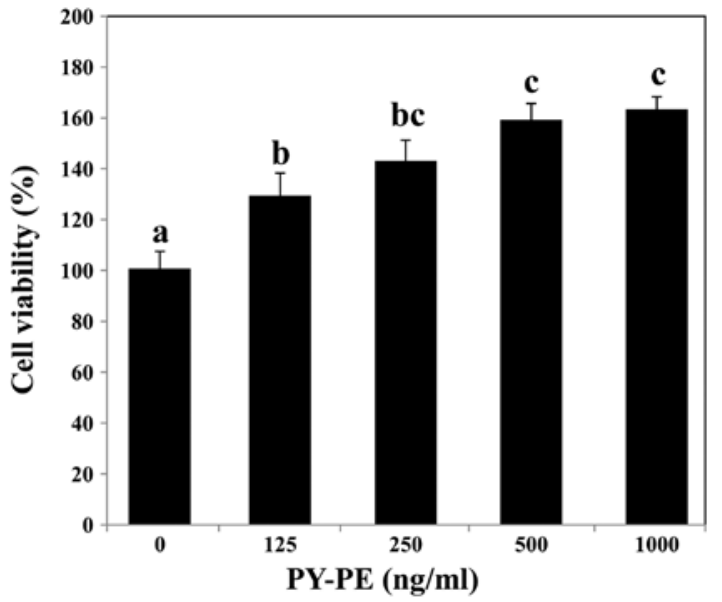

Figure 2. Proliferative effect of $P$. yezoensis (PY-PE) on IEC-6 cells. Cells were seeded in 96-well plates at a density of $1 \times 10^{4}$ cells/well with $10 \%$ fetal bovine serum-supplemented medium. After incubation for $24 \mathrm{~h}$, the cells were serum-starved for $4 \mathrm{~h}$ and treated with PY-PE at the indicated concentrations for $24 \mathrm{~h}$. The results are presented as the means \pm standard deviation of the three independent experiments.

SPSS version 10.0 (SPSS Inc., Chicago, IL, USA). P<0.05 was considered to indicate a statistically significant difference.

\section{Results}

Proliferative effect of PY-PE in IEC-6 cells. Through mass spectrometry, a 1,916-kDa compound was identified from P. yezoensis, which was designated as PY-PE (Fig. 1). The proliferative effect of PY-PE on IEC-6 cells was confirmed using MTS assay. Treatment with PY-PE for $24 \mathrm{~h}$ increased cell viability in a dose-dependent manner (Fig. 2).

Effect of PY-PE treatment on the expression of IGF-IR-related proteins. To confirm the mechanism of PY-PE-induced proliferation in IEC-6 cells, the effects of PY-PE were examined on IGF-IR signaling pathway-related proteins. The protein and mRNA expression levels of IGF-IR, IRS-1, Shc and PY-99 in IEC-6 cells treated with PY-PE (125, 250, 500 and $1,000 \mathrm{ng} / \mathrm{ml}$ ) for $24 \mathrm{~h}$ were determined by western blotting and RT-PCR. Treatment with PY-PE dose-dependently upregulated the protein (Fig. 3A) and mRNA (Fig. 3B) expression levels of IGF-IR, IRS-1, Shc and PY-99. IGF-IR stimulates the proliferation of various cell types and inhibits apoptosis (25).

Effect of PY-PE treatment on the expression of MAPK signaling pathway proteins. To further investigate the downstream signals regulated by IGF-IR activation, the expression levels of the MAPK family proteins (ERK1/2, JNK and P38) in IEC-6 cells treated with PY-PE $(125,250,500$ and 1,000 $\mathrm{ng} / \mathrm{ml})$ for $24 \mathrm{~h}$ were determined by western blot analysis. Treatment with PY-PE dose-dependently increased the protein expression level of ERK1/2. By contrast, PY-PE treatment inhibited the activation of JNK and p38 in dose-dependent manners (Fig. 4). These results suggest that ERK1/2 plays an important role in the proliferation of IEC- 6 cells.

Effect of PY-PE treatment on the expression of PI3K-Akt signaling pathway proteins. The expression levels of the 
$\mathbf{A}$

$$
\text { PY-PE (ng/ml) }
$$

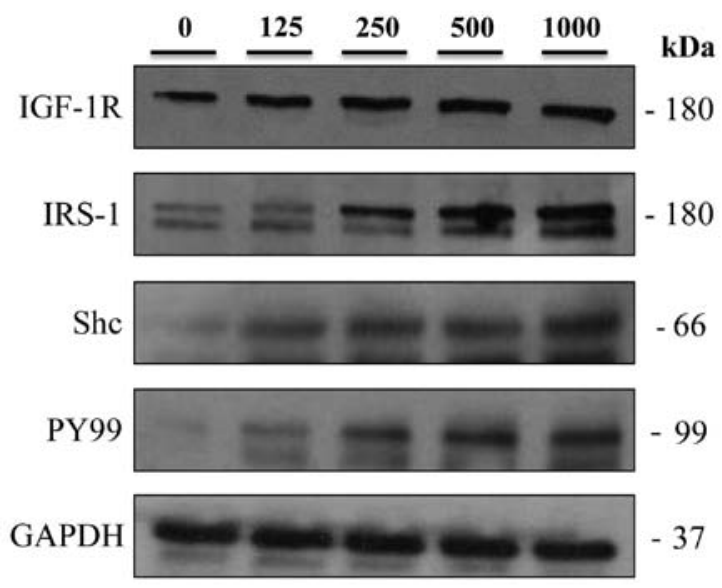

B

PY-PE (ng/ml)

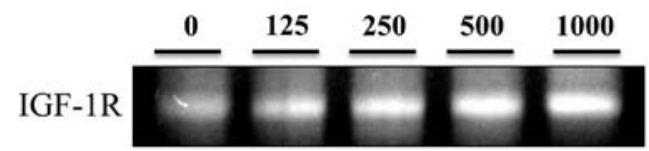

IRS-1

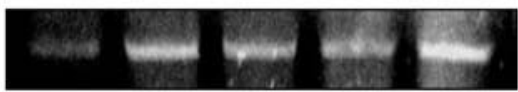

GAPDH

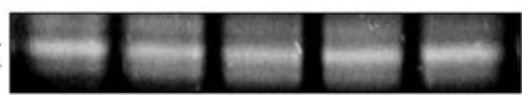

Figure 3. Effect of P. yezoensis (PY-PE) treatment on IGF-IR, IRS-1, Shc and PY-99 protein and mRNA expression levels in IEC-6 cells. Protein expression was examined by western blotting, and cDNA was subjected to RT-PCR analysis. (A) Protein expression levels were increased upon incubation with PY-PE for 24 h. (B) mRNA expression levels were also increased. IGF-IR, insulin-like growth factor-I receptor; IRS-1, insulin receptor substrate-1; RT-PCR, reverse transcription-polymerase chain reaction..

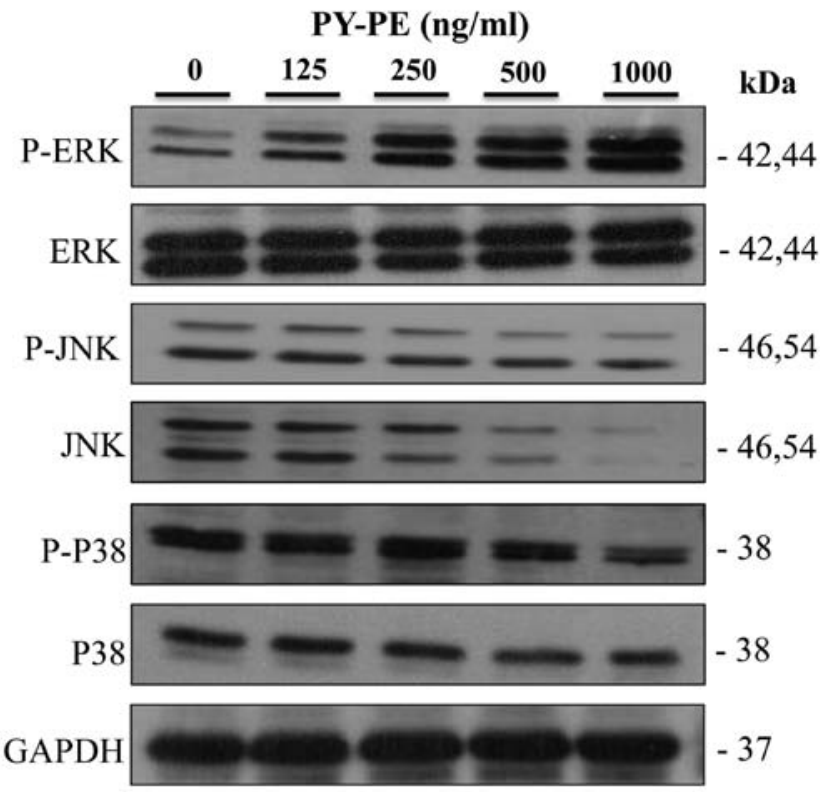

Figure 4. Effect of P. yezoensis (PY-PE) treatment on the mitogen-activated protein kinase (MAPK) signaling pathway. Whole-cell extracts were prepared and analyzed by western blotting using anti-phospho-extracellular signal-regulated kinase 1/2 (ERK1/2), anti-ERK, anti-phospho-c-Jun $\mathrm{N}$-terminal kinase (JNK), anti-JNK, anti-phospho-p38, anti-p38 and anti-glyceraldehyde 3-phosphate dehydrogenase (GAPDH) antibodies.
A

PY-PE (ng/ml)

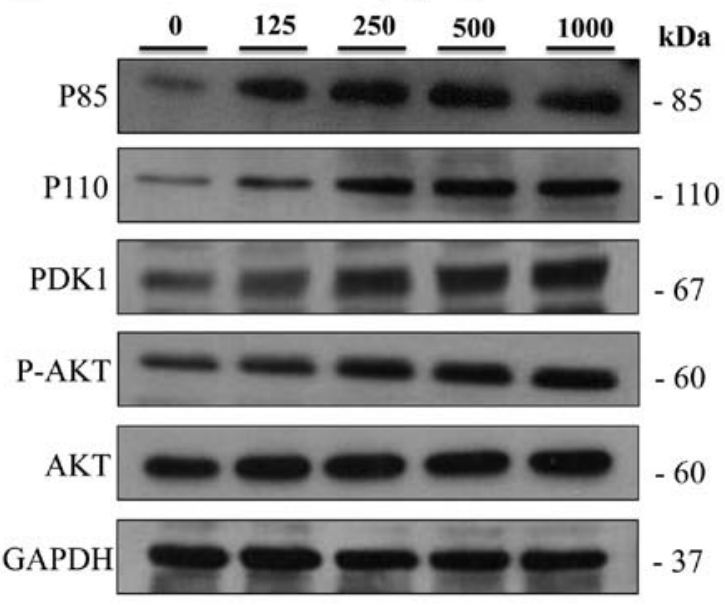

B

PY-PE (ng/ml)

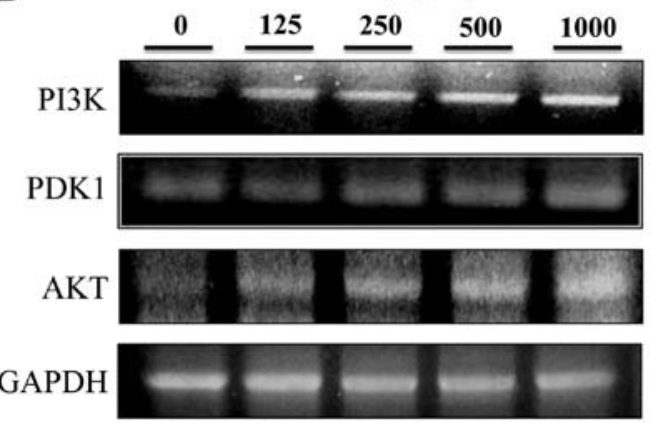

Figure 5. Effect of P. yezoensis (PY-PE) treatment on phosphatidylinositol 3-kinase (PI3K) (p85 and p110), Akt and phosphoinositide-dependent protein kinase 1 (PDK1) (A) protein and (B) mRNA expression levels in IEC-6 cells. Whole-cell extracts were prepared and analyzed by western blot analysis using anti-p85, anti-p110, anti-PDK1, anti-phospho-Akt, anti-Akt and anti-glyceraldehyde 3-phosphate dehydrogenase (GAPDH) antibodies.
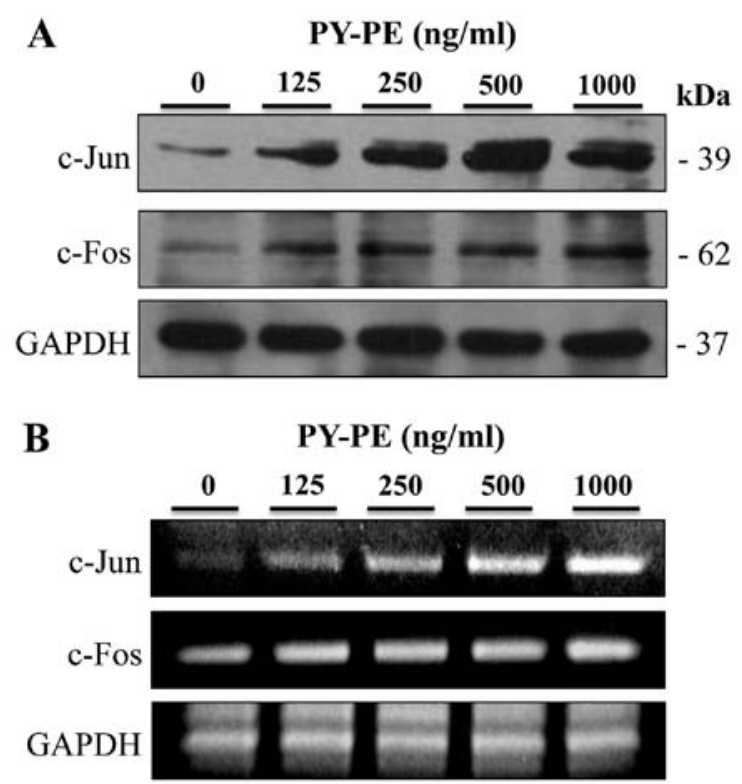

Figure 6. Effect of P. yezoensis (PY-PE) treatment on c-Jun and c-Fos (A) protein and (B) mRNA expression levels in IEC-6 cells. Cells were treated with PY-PE after preincubation with serum-free medium (SFM) for $4 \mathrm{~h}$. Nuclear extracts were prepared and analyzed by western blotting using anti-c-Jun, anti-c-Fos and anti-glyceraldehyde 3-phosphate dehydrogenase (GAPDH) antibodies. 
PI3K-Akt signaling pathway intermediates were examined by western blotting and RT-PCR. PY-PE treatment for $24 \mathrm{~h}$ resulted in increased protein and mRNA expression levels of p85, p110, PDK1 and p-Akt compared to the controls (Fig. 5).

Effect of PY-PE treatment on the expression of AP-1. IGF-IR activates the PI3K/Akt and p42/p44 MAPK pathways, which regulate the activation of transcription factors, such as AP-1 (26). AP-1 regulates cell proliferation and survival. Therefore, AP-1 protein and mRNA expression levels were examined by western blot analysis and RT-PCR, respectively. PY-PE treatment of IEC- 6 cells upregulated the protein and mRNA expression levels of c-Jun and c-fos compared to the controls (Fig. 6).

\section{Discussion}

Numerous types of seaweed are important sources of physiologically active substances, such as peptides and polysaccharides, and have shown medicinal benefits, including anti-ulcer, antitumor, antibacterial, antioxidant and antiviral activities (27-29).

The purpose of the present study was to determine whether PY-PE induced proliferation of IEC-6 cells and to identify the associated signals. In an MTS assay, exposure to PY-PE for $24 \mathrm{~h}$ had dose-dependent effects on the proliferation of IEC-6 cells (Fig. 2). The mechanism associated with this proliferative effect was subsequently examined. The regulation of cell proliferation is dependent on various signaling pathways. In the present study, the IGF-IR signaling pathway was the main focus.

IGF-IR regulates the biological activity of IGF-I and plays critical roles in cell growth, differentiation and proliferation. Additionally, adaptor proteins, such as IRS-1, Shc and PY-99, have all been indicated in sending signals to the cell nucleus $(7,30)$. The results of the present study showed that PY-PE increased the protein and mRNA expression levels of IGF-IR, IRS-1, Shc and PY-99 (Fig. 3). Following IGF-IR activation, downstream signaling pathways, including the PI3K and p42/p44 MAPK pathways, are activated (31). The MAPK family in mammalian cells includes ERK-1/2, JNK, SAPK and p38 kinase (32). ERK1/2 is activated primarily in response to mitogens and growth factors. This pathway plays an important role in cell proliferation, growth and survival (33-35). By contrast, JNK and p38 are mostly activated by cellular stress and by cytokines (36). In the present study, in accordance with PY-PE-induced cell proliferation, ERK1/2, a critical mediator that regulates cell growth and proliferation, was activated by exposure to PY-PE. By contrast, PY-PE treatment did not induce phosphorylation of JNK or p38 (Fig. 4).

The present results showed that IGF-IR activation also contributes to PY-PE-induced cell proliferation through activation of the PI3K/Akt pathway, a key intracellular signaling pathway that regulates multiple cellular processes, including cell survival, growth and proliferation (37). PI3K is a heterodimeric protein composed of two subunits: A p85 regulatory subunit $(85 \mathrm{kDa})$ and a p110 catalytic subunit $(110 \mathrm{kDa})(38,39)$. Once the p85 regulatory subunit is positioned appropriately, the p110 catalytic subunit of PI3K generates phosphatidylinositol 3,4,5-triphosphate, which in turn activates various downstream targets, including the serine/threonine kinase Akt $(40,41)$. In the present study, PY-PE increased the protein and mRNA expression levels of p85, p110 and PDK1, as well as Akt phosphorylation (Fig. 5).

In a wide range of systems, it has been well established that growth factor ligation leads to activation of the p42/p44 MAPK and PI3K/Akt pathways, resulting in the activation of various transcription factors (42). For instance, platelet-derived growth factor activates the $\mathrm{p} 42 / \mathrm{p} 44$ MAPK pathway, which modulates AP-1 activation, in NIH 3 T3 mouse fibroblasts $(43,44)$. Therefore, PY-PE-induced cell proliferation was assumed to involve AP-1. These results show that PY-PE increased the protein and mRNA expression levels of c-Jun and c-fos (Fig. 6).

In conclusion, PY-PE stimulated the proliferation of IEC-6 normal intestinal epithelial cells. This effect was also associated with the IGF-IR signaling pathway. Therefore, PY-PE may be a potential component of bio-functional foods with a proliferative effect on intestinal epithelial cells.

\section{Acknowledgements}

The present study was supported by the Basic Science Research Program through the National Research Foundation of Korea (NRF) funded by the Ministry of Education (grant no. 2012R1A6A1028677).

\section{References}

1. Chopin T, Yarish C, Wilkes R, Belyea E, Lu S and Mathieson A: Developing Porphyra/salmon integrated aquaculture or bioremediation and diversification of the aquaculture industry. J Appl Phycol 11: 463-472, 1999.

2. Kwon MJ and Nam TJ: Porphyran induces apoptosis related signal pathway in AGS gastric cancer cell lines. Life Sci 79: 1956-1962, 2006.

3. Shin ES, Hwang HJ, Kim IH and Nam TJ: A glycoprotein from Porphyra yezoensis produces anti-inflammatory effects in liposaccharide-stimulated macrophages via the TLR4 signaling pathway. Int J Mol Med 28: 809-815, 2011.

4. Liu F, Liu J, Zhang L, Shen W, Guo T, Liu C and He P: Ex vivo anti-oxidation activity of polysaccharides from the red alga Porphyra yezoensis. Res J Pharmacol 1: 61-66, 2007.

5. Suetsuna K: Purification and identification of angiotensin I-converting enzyme inhibitors from the red alga Porphyra yezoensis. J Mar Biotechnol 6: 163-167, 1998.

6. Lee AV and Yee D: Insulin-like growth factor and breast cancer. Biomed Pharmacother 49: 415-421, 1995.

7. Butler AA, Yakar S, Gewolb IH, Karas M, Okubo Y and LeRoith D: Insulin-like growth factor-I receptor signal transduction: at the interface between physiology and cell biology. Comp Biochem Physiol B Biochem Mol Biol 121: 19-26, 1998.

8. Guvakova MA and Surmacz E: Tamoxifen interferes with the insulin-like growth factor I receptor (IGF-IR) signaling pathway in breast cancer cells. Cancer Res 57: 2606-2610, 1997.

9. Pelicci G, Lanfrancone L, Salcini AE, et al: Constitutive phosphorylation of Shc proteins in human tumors. Oncogene 11: 899-907, 1995.

10. Habib T, Herrera R and Decker SJ: Activators of protein kinase C stimulate association of Shc and the PEST tyrosine phosphatase. J Biol Chem 269: 25243-25246, 1994.

11. Rhodes CJ and White MF: Molecular insights into insulin action and secretion. Eur J Clin Invest 32: 3-13, 2002.

12. Annunziata M, Cranata R and Ghigo E: The IGF system. Acta Diabetol 48: 1-9, 2011

13. Krasilnikov MA: Phosphatidylinositol-3 kinase dependent pathways: the role in control of cell growth, survival, and malignant transformation. Biochemistry (Mosc) 65: 59-67, 2000.

14. Latres E, Amini AR, Amini AA, et al: Insulin-like growth factor-1 (IGF-1) inversely regulates atrophy-induced genes via the phosphatidylinositol 3-kinase/Akt/mammalian target of rapamycin (PI3K/Akt/mTOR) pathway. J Biol Chem 280: 2737-2744, 2005 
15. Guha M and Mackman N: The phosphatidylinositol 3-kinase-Akt pathway limits lipopolysaccharide activation of signaling pathways and expression of inflammatory mediators in human monocytic cells. J Biol Chem 277: 32124-32132, 2002.

16. Cantley LC: The phosphoinositide 3-kinase pathway. Science 296: 1655-1657, 2002.

17. Junttila MR, Li SP and Westermarck J: Phosphatase-mediated crosstalk between MAPK signaling pathways in the regulation of cell survival. FASEB J 22: 954-965, 2008

18. Roux PP and Blenis J: ERK and p38 MAPK-activated protein kinases: a family of protein kinases with diverse biological functions. Microbiol Mol Biol Rev 68: 320-344, 2004.

19. Weston GR and Davis RJ: The JNK signal transduction pathway. Curr Opin Cell Biol 19: 142-149, 2007.

20. Karin M, Liu ZG and Zandi E: AP-1 function and regulation. Curr Opin Cell Biol 9: 240-246, 1997.

21. Karin M: The regulation of AP-1 activity by mitogen-activated protein kinases. J Biol Chem 270: 16483-16486, 1995.

22. Shaulian E and Karin M: AP-1 in cell proliferation and survival. Oncogene 20: 2390-2400, 2001.

23. Marais R, Wynne J and Treisman R: The SRF accessory protein Elk-1 contains a growth factor regulated transcription activation domain. Cell 73: 381-393, 1993.

24. Gopalakrishnan A, Xu CJ, Nair SS, Chen C, Hebbar V and Kong AN: Modulation of activator protein-1 (AP-1) and MAPK pathway by flavonoids in human prostate cancer PC3 cells. Arch Pharm Res 29: 633-644, 2006.

25. Song SH, Kim IH and Nam TJ: Effect of a hot water extract of Chlorella vulgaris on proliferation of IEC-6 cells. Int J Mol Med 29: 741-746, 2012.

26. Bancroft C, Chen Z, Yeh J, et al: Effects of pharmacologic antagonists of epidermal growth factor receptor, PI3K and MEK signal kinases on NF-kappaB and AP-1 activation and IL-8 and VEGF expression in human head and neck squamous cell carcinoma lines. Int J Cancer 99: 538-548, 2002.

27. Gómez-Ordóñez E, Jiménez-Escrig A and Rupérez P: Effect of the red seaweed Mastocarpus stellatus intake on lipid metabolism and antioxidant status in healthy Wistar rats. Food Chem 135: 806-811, 2012.

28. Ronghai H, Haile M and Xinzheng L: Ultrasonic extraction of polysaccharides from Porphyra yezoensis and their inhibition effects in U937 cell growth. Trans CSAE 21: 165-168, 2005.

29. Costa LS, Fidelis GPL, Cordeiro SL, et al: Biological activities of sulfated polysaccharides from tropical seaweeds. Biomed Pharmacother 64: 21-28, 2010.

30. Wang Y, Hailey J, Williams D, et al: Inhibition of insulin-like growth factor-I receptor (IGF-IR) signaling and tumor cell growth by a fully human neutralizing anti-IGF-IR antibody. Mol Cancer Ther 4: 1214-1221, 2005.
31. Starkman B, Cravero J, Delcarlo $M$ and Loeser R: IGF-I stimulation of proteoglycan synthesis by chondrocytes requires activation of the PI3-Kinase pathway but not ERK MAPK. Biochem J 389: 723-729, 2005.

32. Zhang W and Liu HT: MAPK signal pathways in the regulation of cell proliferation in mammalian cells. Cell Res 12: 9-18, 2002.

33. Ballif BA and Blenis J: Molecular mechanisms mediating mammalian mitogen-activated protein kinase (MAPK) kinase (MEK)-MAPK cell survival signals. Cell Growth Differ 12: 397-408, 2001

34. Rubinfeld $\mathrm{H}$ and Seger R: The ERK cascade: a prototype of MAPK signaling. Mol Biotechnol 31: 151-174, 2005.

35. Meloche S and Pouysségur J: The ERK1/2 mitogen-activated protein kinase pathway as a master regulator of the G1- to S-phase transition. Oncogene 26: 3227-3239, 2007.

36. Davis RJ: Signal transduction by the JNK group of MAP kinases. Cell 103: 239-252, 2000.

37. Go H, Hwang HJ and Nam TJ: Glycoprotein extraction from Laminaria japonica promotes IEC-6 cell proliferation. Int J Mol Med 24: 819-824, 2009.

38. Kapeller R and Cantley LC: Phosphatidylinositol 3-kinase. Bioessays 16: 565-576, 1994

39. Carpenter CL, Duckworth B, Auger K, Cohen B, Schaffhausen B and Cantley LC: Purification and characterization of phosphoinositide 3-kinase from rat liver. J Biol Chem 265: 19704-19711, 1990.

40. Morgan S and Grandis JR: ErbB receptors in the biology and pathology of the aerodigestive tract. Exp Cell Res 315: 572-582, 2009.

41. Jiang BH, Aoki M, Zheng JZ, Li J and Vogt PK: Myogenic signaling of phosphatidylinositol 3 -kinase requires the serine-threonine kinase Akt/protein kinase B. Proc Natl Acad Sci USA 96: 2077-2081, 1999.

42. Qiu Q, Yang M, Tsang BK and Gruslin A: EGF-induced trophoblast secretion of MMP-9 and TIMP-1 involves activation of both PI3K and MAPK signalling pathways. Reproduction 128: 355-363, 2004.

43. Lavarone C, Catania A, Marinissen MJ, Visconti R, Acunzo M, Tarantio $\mathrm{C}$, et al: The platelet-derived growth factor controls c-myc expression through a JNK-and AP-1-dependent signaling pathway. J Biol Chem 278: 50024-50030, 2003.

44. Monje P, Marinissen MJ and Gutkind JS: Phosphorylation of the carboxyl-terminal transactivation domain of c-Fos by extracellular signal-regulated kinase mediates the transcriptional activation of AP-1 and cellular transformation induced by platelet-derived growth factor. Mol Cell Biol 23: 7030-7043, 2003. 